\title{
Review on Production of Liquid Fuel from Co-Pyrolysis of Biomass with Scrap/Waste Tire
}

\author{
${ }^{1}$ BABAJO, SA; ${ }^{2}$ ENABUREKHAN, JS; ${ }^{3}$ RUFAI, IA \\ ${ }^{1}$ Department of Mechanical Engineering, Modibbo Adama University of Technology, Yola, Nigeria \\ ${ }^{2,3}$ Department of Mechanical Engineering, Bayero University, Kano, Nigeria \\ *Corresponding Author Email: bbjosul@gmail.com, Tel: +2348034343083
}

\begin{abstract}
The oil produced by the pyrolysis of biomass has potential for use as a substitute for fossil fuels. However, the oil needs to be upgraded since it contains high levels of oxygen, which causes low calorific value, corrosion problems, and instability. Generally, upgrading the pyrolysis oil involves the addition of a catalyst, solvent and large amount hydrogen, which can cost more than the oil itself. In this regard, the co-pyrolysis technique offers simplicity and effectiveness in order to produce a high-grade pyrolysis oil. Co-pyrolysis is a process which involves two or more materials as feedstock. The feedstocks were biomass and tire waste. The pyrolysis of scrap tires at a temperature of $500^{\circ} \mathrm{C}$ produced an oil yield of $44.1 \mathrm{wt} \%$. The increase in oil yield from co-pyrolysis processes of Pine wood and tire wastes was found to be $64.8 \mathrm{wt} \%$. The HHV of tire waste pyrolysis liquid alone was $43.8 \mathrm{MJ} / \mathrm{kg}$ while for the co-pyrolysis of tire waste and pinewoods was $46.8 \mathrm{MJ} / \mathrm{Kg}$. The results of many studies showed that the use of co-pyrolysis technique can improve the characteristics of pyrolysis oil, e.g., increase the oil yield, reduce the oxygen content, reduce the water content, and increase the calorific value of the oil.
\end{abstract}

DOI: $\underline{\text { https://dx.doi.org/10.4314/jasem.v23i8.10 }}$

Copyright: Copyright (C) 2019 Babajo et al. This is an open access article distributed under the Creative Commons Attribution License (CCL), which permits unrestricted use, distribution, and reproduction in any medium, provided the original work is properly cited.

Dates: Received: 14 June 2019; Revised: 30 July 2019; Accepted 10 August 2019

Keywords: Co-pyrolysis, Biomass, Tire-waste and Calorific-value

Introduction: The decrease of fossil fuel resources such as coal, petroleum, and natural gas has encouraged research to develop new approaches to find or invent renewable fuel. One article has predicted that the coal reserves will be available until at least by the year 2112, and it will be the sole fossil fuel in the world after 2042 (Shafee and Topal, 2009). Several efforts are currently underway to find alternative energy sources and develop technologies which have high efficiency and are environmentally- friendly. In this regard, most of the effort has been contributed by research into biomass energy. During the last three decades, more than half of the global research has been focused on biomass as renewable energy (56\%), followed by solar energy (26\%), wind power $(11 \%)$, geothermal energy (5\%), and hydropower $(2 \%)$ (Manzo et al., 2013). The high percentage of research into biomass energy can be supported by the availability of biomass resources which are the world's largest sustainable energy source and represent approximately 220 billion dry tons of annual primary production (Moreira, 2006). Beside the effect of decreasing of fossil fuels, environmental concerns also play an important role in the development of renewable energy. The risk and reality of environmental concerns have drastically increased globally and become more apparent during the past decade, particularly after Earth Summit '92 (Agarwal, 2006). To minimize environmental concerns, it is necessary to consider controlling the pollutant emissions. The optimal use of renewable energy resources can be an optional solution since it significantly contributes to decreasing the negative environmental impacts, reducing the dependence on the use of fossil fuels, and is followed by an increase of net employment and the creation of export markets (Manzo et al., 2013).Biomass is widely accepted as a potential source of energy and is the only renewable energy source that can be converted into several types of fuels, including liquid, char, and gas, which also promise flexibility in production and marketing. Pyrolysis is generally chosen as a recommended process to achieve this goal. This process has received more attention recently because it can produce the highest liquid yield of up to $75 \mathrm{wt} \%$ with conditions of moderate temperature $\left(500^{\circ} \mathrm{C}\right)$ and short hot vapor residence time (-1 s) (Ceulian et al., 2009; Bridgewater, 2006). Nevertheless, the yield of other products also can be optimized by adjusting the parameters of operating conditions. The liquid from the pyrolysis process is known as pyrolysis oil or biooil, and has potential as use for fuels or feedstock for many commodity chemicals. In terms of fuels, Bridgwater et al. (1999) noted that without an 
upgrading process, the oil can be directly used in many applications including boilers, furnaces, diesel engines, and turbines for the generation of electricity. In addition, the greatest advantage of pyrolysis oil compared with fossil fuel is that the use of this oil has received positive comments as a more environmentally-friendly fuel because it contributes minimally to the emission of greenhouse gases (Vitolo et al., 1999). Despite the oil from pyrolysis being environmentally-friendly, the fuel characteristic of it remains lower than fossil fuel, especially with regard to combustion efficiency. In this case, the high composition of oxygenated compounds in pyrolysis oil is responsible for this problem. Several researchers have reported that oil from the pyrolysis of biomass generally contains an oxygen content of around 35-60 wt\% (Athikoski, 2008; Parihar et al., 2007; Bridgewater, 2006; Oasma and Czemik, 1999;). It can be identified in the form of more than 200 different compounds in the oils, and is mostly found as water (Oasma and Czemik, 1999). However, the high level of oxygen in pyrolysis oil creates a low calorific value, corrosion problems and instability (Bridgewater, 2012).

Importance of the Co-Pyrolysis Process: Simplicity and effectiveness are especially important in developing a technique to produce the ideal synthetic liquid fuel. In this regard, the idea of co-pyrolysis of biomass can be an optional technique that shows promise by meeting these two criteria. Co-pyrolysis is a process which involves two or more different materials as a feedstock. Many studies have shown that the co-pyrolysis of biomass has successfully improved the oil quantity and quality without any improvement in the system process. In contrast to catalytic cracking and HDO, co-pyrolysis has shown promise for future application in industry because of its attractive performance/cost ratios. The successful key of this technique mainly lies with the synergistic effect which comes from the reaction of different materials during the process. A previous study has shown that the yield of oil obtained from incorporating plastic was higher than that obtained with woody biomass alone and also had a higher calorific value, which comes from hydrocarbon polymers consisting of paraffins, isoparaffins, olefins, naphthenes and aromatics, and a non-condensable gas with a high calorific value (Toba et al., 2011). The idea of blending oil from biomass with oil from tire seems impossible, and may increase operation costs. Oil from biomass cannot be completely mixed with oil from waste tire because of the polar nature of pyrolysis oil of biomass. If these oils are mixed together, an unstable mixture forms, which breaks (phase separation) after a short period of time. If pyrolysis of biomass and tire waste occurs independently or separately more energy is required and the cost for oil production will significantly increase. The copyrolysis technique is found to be more reliable to produce homogenous pyrolysis oil than the blending oil method. The interaction of radicals during the copyrolysis reaction can promote the formation of a stable pyrolysis oil that avoids phase separation (Martinez et al., 2014). Furthermore, the main benefit of using co-pyrolysis method is the fact that the volume of waste can be reduced significantly as more waste is consumed as feedstock. It also has the added benefits of reducing the landfill needed, saving costs for waste treatment, and solving a number of environmental problems. Since the disposal of waste in landfills is undesirable (Garfoth et al, 2014), this method could be proposed as an alternative waste management procedure for the future that will have a significant impact on waste reduction and may enhance energy security. In addition, from an economic point of view, co-pyrolysis has been found to be a promising option for a biomass conversion technique to produce pyrolysis oil. Kuppens et al. (2010) investigated the economic consequences of the synergetic effects of flash co-pyrolysis. They concluded that the use of co-pyrolysis techniques is more profitable than pyrolysis of biomass alone and that it also has potential for commercial development.

Mechanism of the Co-Pyrolysis Process: The mechanisms of co-pyrolysis and normal pyrolysis are almost the same. Basically, the process is performed in a closed reactor system with moderate operating temperatures and in the absence of oxygen. For the purposes of oil production, there are three basic steps required for the co-pyrolysis process: preparation of samples, co-pyrolysis, and condensation. Figure 1, illustrates the pyrolysis set up to produce liquid fuel. Prior to co-pyrolysis, the samples should be dried and ground. The drying process can be performed using the oven method (temperature at $105^{\circ} \mathrm{C}$ for $24 \mathrm{~h}$ ). For industrial application, the heat demand for feedstock drying can be covered by internal heat sources through process integration. Researchers suggested that the byproducts char or gas can be combusted to provide the necessary heat for endothermic pyrolysis and other intermediate processes, such as biomass drying (Vendebosch and Prins, 2010; Veses et al., 2012). The main aim of the drying process is removing the moisture content of sample. High moisture content in feed results in the oil product having a high water content; therefore, Bridgwater (2012) suggested that the maximum moisture content in the dried feed material should be $10 \%$. The dried samples also benefit from the grinding process, and small biomass particles with a size of less than 2-3 $\mathrm{mm}$ are needed to 
achieve high biomass heating rates (Bridgwater, 2012). There is an optional feature in the co-pyrolysis process: inert gas. Inert gas is used to accelerate sweeping vapors from the hot zone (pyrolysis zone) to the cool zone (condenser). Short hot vapor residence times of less than $2 \mathrm{~s}$ are needed to minimize secondary reactions and maximize oil yield (Bridgwater, 2012). In application, nitrogen $\left(\mathrm{N}_{2}\right)$ is an inert gas that is commonly used since it is found to be cheap compared to others. Many studies have proven that the use of inert gases in the pyrolysis process has an effect on liquid yield (Demiral and Sensoz 2006; Achikogz et al., 2015). The proper setting of the inert gas flow rate is needed to attain maximum oil yield, while very high flow rates of inert gas actually decrease the total oil yield. However, the use of inert gas is dependent on the type of reactor used. The fluid bed reactor, circulating fluid bed reactor, and entrained flow reactor are the types which need a high flow rate of inert gas (Vamvuka, 2011). For vacuum, fixed bed and ablative reactors, the use of inert gas is not compulsory. Furthermore, the pyrolysis process is also influenced by many parameters, including the type of biomass, temperature, heating rate, reaction time, and particle size of feed. Detailed discussions of the effect of parameters on optimum oil yield in the pyrolysis of biomass have been thoroughly reviewed by Akhtar and Amin (2012). For co-pyrolysis, as a general rule, temperature can be adjusted within the range of 400 $600^{\circ} \mathrm{C}$ to maximize the production of oil. In this temperature range, more than $45 \mathrm{wt} \%$ oil can be produced. However, the optimum temperature required to produce the maximum oil yield is dependent on the characteristics of feedstock. Therefore, characterization with regard to proximate and ultimate analysis should be performed to obtain an overview of the behavior of material (Velghe et al., 2015). Condensation is an important step in the production of pyrolysis oil. Without this step, only the char and gas products can be obtained from the process. The vapors generated during the process pass through the condensation unit to change the physical state of matter from the gas phase into the liquid phase. Vapor product residence time in the reactor can be controlled by the addition of inert gas. Bridgwater (1999) noted that pyrolysis vapors can be characterized as a combination of true vapors, micronsized droplets and polar molecules bonded with water. Rapid cooling of the pyrolysis vapors is required to produce a high liquid yield. The lower vapor temperature $\left(<400^{\circ} \mathrm{C}\right)$ leads to secondary condensation reactions and the average molecular weight of the liquid product decreases. Thus, the temperature in pipelines from the pyrolysis unit to the condensation unit should be maintained at $>400^{\circ} \mathrm{C}$ to minimize liquid deposition; also, blockage of the equipment and piping system should be avoided (Bridgewater et al., 1999).

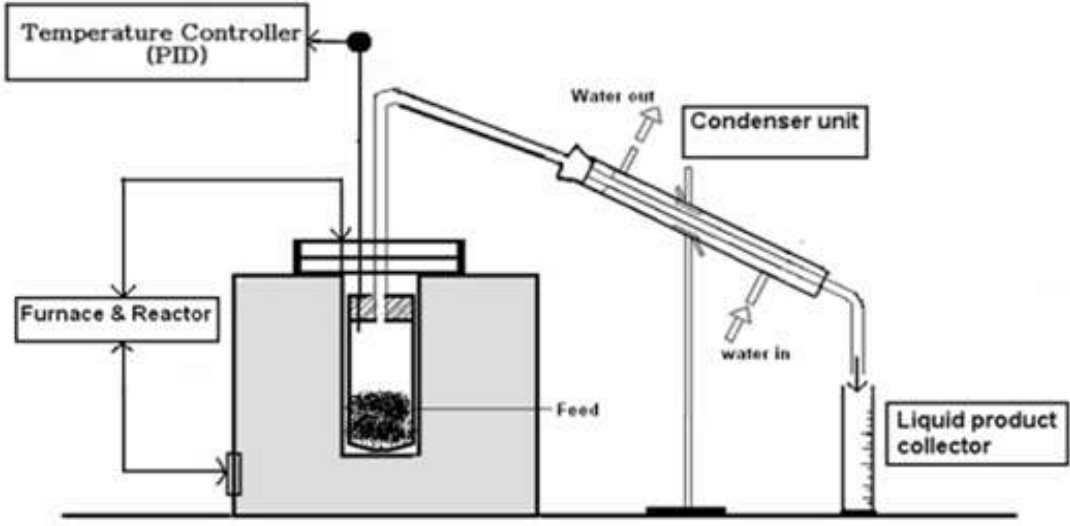

Fig. 1: Pyrolysis set up
Feedstock for The Co-Pyrolysis Process: A diversity of renewable energy resources can be found around the world, including biomass energy, wind energy, solar energy and geothermal energy. Among these, biomass is the only source of renewable energy that can produce fuels in the form of solid, liquid and gas, through assistance of the pyrolysis process. Although fuels from biomass, especially wood-based biomass, typically have a lower energy content than fossil fuels, the use of co-pyrolysis technology is improving this condition. In this section, the discussion only focused on the selection and availability of feedstock which can potentially be used in the co-pyrolysis process.

Selection of feedstock: Some types of biomass have the potential for use in the co-pyrolysis process to improve the quality and quantity of pyrolysis oil. In this regard, the selection of biomass wastes is becoming an important issue requiring study. Currently, many kinds of biomass have been successfully used as feedstock in the co-pyrolysis process in research, which can be categorized into four groups: 
Availability of the Feedstock: An important criterion for selecting the proper materials as alternative energy sources is its availability. In this context, biomass has been found to be sufficient for meeting this criterion. Biomass can be obtained from forestry residues, agricultural residues, agro-industrial wastes, animal wastes, industrial wastes, sewage, municipal solid wastes, and food processing wastes; thus, as consequence, the total accumulation of biomass will always be high. Each country has different sources of biomass depending on a number of factors such as geographical conditions, population levels, economic development, agricultural development, forest development, industrial growth, food demand and lifestyle. This means that all of the countries in the world have the same opportunities with regard to the co-pyrolysis process for the production of liquid fuel from biomass.

Around 1.5 billion tires are produced worldwide every year, which will eventually be categorized or interpreted as waste tires (Wiliams, 2017). Waste tires are known to have a significant impact on increasing the urban waste stream and it will become a major threat to the environment. Approximately $64 \%$ of waste tires are sent to landfill or illegally dumped or stockpiled, with only $13 \%$ of them being recycled (Quek, 2017). In landfills, waste tires are not easily degraded, but tend to float to the top over time due to trapped gases, thus breaking landfill covers. The incineration of waste tires requires the expensive control system of air emissions because this process produces toxic gases, which contain carcinogenic and mutagenic chemicals. Special treatment and attention are needed to tackle waste tires, and pyrolysis has been found to be a technically feasible way to treat tires and recover valuable products. Wastes of plastics and tires are considered to be potential sources to use as a cofeed in co-pyrolysis to produce liquid fuel. As well as those materials having high energy content, the sources are particularly easy to find and available in huge amounts in all countries around the world. Pyrolysis of the blends of those materials with other biomass wastes will encourage the creation of innovative new concepts in waste management, energy security enhancement, and environmental concerns. Therefore, it is important to note that development of the co-pyrolysis process to produce liquid fuel may be applicable in most countries.

Exploration of Co-Pyrolysis Studies: The exploration of co-pyrolysis studies is necessary in order to generate ideas with regard to producing high-grade pyrolysis oil. For this reason, many efforts have been made by researchers to explore this technique, and have revealed many interesting findings. An overview of studies of the co-pyrolysis of biomass wastes with emphasis on pyrolysis oil production is described below.

Use of Scrap/Waste Tires in Co-pyrolysis: There is growing interest among researchers in the use of waste tires as a fuel source through the process of pyrolysis. As a research output, several comprehensive reviews on various aspects of waste tires pyrolysis for liquid production have been published in 2017 (Martinez et al., 2017, Wiliams 2017 and Quek 2017). In copyrolysis, many studies of pyrolysis of waste tires mixed with other materials have been carried out. However, studies which focused on the pyrolysis of waste tire/wood-based biomass blends are currently still limited. Therefore, some effort should be made to examine the existence of synergistic effects when employing various pyrolysis conditions for the pyrolysis of waste tire/biomass. Several studies which involved waste tires in the co-pyrolysis process are summarized in Table 1. All of the data summarized in Table 1 were collected from experiments without using catalysts and solvents or any additional pressure. As can be seen from Table 1, the studies of the copyrolysis of biomass and tire waste have been classified into two categories: co-pyrolysis of waste tires with wood-based biomass and co-pyrolysis of waste tires with sawdust and pinewood waste. In studies of the co-pyrolysis of waste tires with woodbased biomass, the addition of waste tires was used with the aim of obtaining extra oil. From the studies performed by Alias et al. (2018) and Cao et al. (2017), it is indicated that the presence of waste tires in the pyrolysis of biomass significantly contributes to the increased oil yield. Furthermore, as tire mass is increased in the pyrolysis of biomass, the calorific value of the oil obviously increases. Therefore, co pyrolysis overcomes a defect of the low calorific value of the oil derived from the pyrolysis of biomass alone.

The second classification in Table 1 is the co-pyrolysis of waste tires with pinewood and saw dust waste. For this classification, waste tires were used to improve the quantity and quality of pyrolysis oil from pinewood and saw dusts. This approach is economical and has great potential as an ecofriendly option. Thus, a proper option to manage waste should be considered, and copyrolysis has been suggested as an alternative technology for conversion of these kinds of waste materials for energy recovery and environmental protection. Onenc et al. (2012) studied co-pyrolysis of scrap tires with pinewoods and concluded that copyrolysis of scrap tires with pinewoods could be an environmentally friendly method for the transformation of hazardous waste into valuable products such as chemicals or fuels. 
Table 1. Relevant review information of co-pyrolysis of waste ire

\begin{tabular}{|c|c|c|c|}
\hline Reference & Materials and Description & $\begin{array}{c}\text { System Configuration and Operation } \\
\text { Conditions }\end{array}$ & Relevant Results and Observations \\
\hline $\begin{array}{l}\text { Alias et al., } \\
2018\end{array}$ & $\begin{array}{l}\text { Waste tires without wire } \\
\text { steel were mixed with } \\
\text { empty fruit bunches with a } \\
\text { ratio of } 1: 1\end{array}$ & $\begin{array}{l}\text { The experiment was performed using a fixed } \\
\text { bed reactor. Co-pyrolysis was carried out } \\
\text { under a nitrogen atmosphere at a temperature } \\
\text { of } 500^{\circ} \mathrm{C} \text {. Pyrolysis oils were collected in an } \\
\text { ice } / \text { water condenser. }\end{array}$ & $\begin{array}{l}\text { The products of liquid, char, and gas were obtained at levels } \\
\text { of } 42.80 \mathrm{wt} \%, 33.20 \mathrm{wt} \% \text {, and } 24.00 \mathrm{wt} \% \text {, respectively. The } \\
\text { liquid product was significantly decreased when the empty } \\
\text { fruit bunches were pyrolyzed alone without being mixed } \\
\text { with waste tires. }\end{array}$ \\
\hline \multirow[t]{2}{*}{$\begin{array}{l}\text { Cao et al., } \\
2017\end{array}$} & $\begin{array}{l}\text { Tire powder with a particle } \\
\text { size less than } 165 \mu \mathrm{m} \text { mixed } \\
\text { with sawdust powder }(198- \\
350 \mu \mathrm{m}) \text {. The ratios of tire } \\
\text { to sawdust in the feed were } \\
\text { varied at } 1: 1,1:: 2 \text { and } 1: 3 \text {. }\end{array}$ & $\begin{array}{l}\text { Feedstock of } 100 \mathrm{~g} \text { was put into the fixed bed } \\
\text { pyrolysis reactor. The reactor was heated to } \\
\text { the designated temperature of } 500^{\circ} \mathrm{C} \text { and } \\
\text { held at that temperature for a period of } 1 \mathrm{~h} \text {. }\end{array}$ & $\begin{array}{l}\text { The liquid yield reached } 45.0 \mathrm{wt} \%, 46.2 \mathrm{wt} \% \text { and } 47.0 \mathrm{wt} \% \\
\text { when tires mass occupied } 25 \%, 50 \% \text {, and } 75 \% \text { in the } \\
\text { mixture respectively. The liquid derived from pyrolysis of } \\
\text { sawdust alone had a HHV of } 28.51 \mathrm{MJ} / \mathrm{kg} \text {, while the value } \\
\text { was increased to } 42.44 \mathrm{MJ} / \mathrm{kg} \text { when tire mass accounted for } \\
50 \% \text { of the mixture. }\end{array}$ \\
\hline & $\begin{array}{l}\text { Pine woodchips }(15 \mathrm{~mm}) \\
\text { containing bark and waste } \\
\text { tires }(5 \mathrm{~mm}) \text { were used for } \\
\text { the experiments }\end{array}$ & $\begin{array}{l}\text { Two reactors with different scales were used } \\
\text { in this study. The first part of the co- } \\
\text { pyrolysis experiment was carried out in a } \\
\text { fiixed bed reactor ( } 74 \mathrm{~cm} \text { length and } 1.6 \mathrm{~cm} \\
\text { internal diameter). The reactor was heated } \\
\text { externally at temperature of } 500^{\circ} \mathrm{C} \text { with a } \\
\text { heating rate of } 80^{\circ} \mathrm{C} / \mathrm{min} \text {. The reaction time } \\
\text { was set to } 15 \mathrm{~min} \text {. Different feedstock } \\
\text { mixtures on mass basis were studied in the } \\
\text { fixed bed reactor: } 100 \% \text { biomass }(100 / 0) \text {; } \\
90 \% \text { biomass and } 10 \% \text { waste tires }(90 / 10) \text {; } \\
80 \% \text { biomass and } 20 \% \text { waste tires }(80 / 20) \\
\text { and } 100 \% \text { waste tires }(0 / 100) \text {. } \\
\text { The auger reactor with a pilot plant scale was } \\
\text { used for second part of the co-pyrolysis } \\
\text { experiment. Experiments were set at } 500{ }^{\circ} \mathrm{C} \\
\text { The residence time of the feedstock inside } \\
\text { the reactor was fixed at } 5 \text { min. }\end{array}$ & $\begin{array}{l}\text { The results from the first part of the experiment showed that } \\
\text { the pyrolysis of biomass alone yielded around } 50.0 \mathrm{wt} \% \text { oil, } \\
\text { whereas the pyrolysis of tire only resulted in about } 47.6 \\
\mathrm{wt} \% \text { oil. Remarkably, } 62.5 \mathrm{wt} \% \text { increase in liquid yield was } \\
\text { observed in the pyrolysis of mixtures of pine woodchips and } \\
\text { waste tires. } \\
\text { For the second experiment, the liquid yield was } 52 \mathrm{wt} \% \text { for } \\
\text { the pyrolysis of pine woodchips. An increase in the liquid } \\
\text { yield was found for the } 90 / 10 \text { blend ( } 56.0 \mathrm{wt} \% \text { ), which was } \\
\text { obviously higher than that for the liquid yield obtained from } \\
\text { a fixed bed reactor ( } 48.5 \mathrm{wt} \% \text { for the } 90 / 10 \text { blend). } \\
\text { The authors noted that the lowest calorific value was } \\
\text { obtained for pyrolysis of the biomass, while the highest was } \\
\text { obtained for the pyrolysis of tires. In addition, all calorific } \\
\text { oils increased with an increased waste tire ratio in the blend. }\end{array}$ \\
\hline $\begin{array}{l}\text { Ucar et al. } \\
\quad 2016\end{array}$ & $\begin{array}{l}\text { Two different types of scrap } \\
\text { tires, passenger car tire } \\
\text { (PCT) and truck tire (TT), } \\
\text { were mixed with biomass } \\
\text { waste. Both tires were } \\
\text { ground to the desired } \\
\text { particle size of } 1.5-2.0 \mathrm{~mm} \text {. } \\
\text { The scrap tires contained no } \\
\text { steel thread or textile } \\
\text { netting. Each tire was mixed } \\
\text { with an equal ratio of waste } \\
\text { biomass (Potato skin) }\end{array}$ & $\begin{array}{l}\text { Co-pyrolysis experiments were carried out } \\
\text { in a fixed bed reactor at temperatures of } 400 \text {, } \\
450 \text { and } 500^{\circ} \mathrm{C} \text {. Liquid products were } \\
\text { condensed in the first two traps by cooling } \\
\text { with water. }\end{array}$ & $\begin{array}{l}\text { The addition of biomass waste in the pyrolysis of scrap tires } \\
\text { is aimed at obtaining extra oil. } \\
\text { The results showed that co-pyrolysis with biomass waste } \\
\text { produced more oil than pyrolysis of tires alone. An } \\
\text { increase in the co-pyrolysis temperature had no effect on the } \\
\text { oil quantity. The calorific values for co-pyrolysis liquids } \\
\text { were slightly higher than those of pyrolysis liquids and } \\
\text { close to those obtained for commercial diesel. }\end{array}$ \\
\hline $\begin{array}{l}\text { Silva et al., } \\
\quad 2013\end{array}$ & $\begin{array}{l}\text { Scrap tire (ST) with a } \\
\text { particle size of less than } 2 \\
\text { mm was mixed with } \\
\text { pinewoods. The ratio of } \\
\text { waste tire and biomass } \\
\text { waste were fixed at } 1: 1\end{array}$ & $\begin{array}{l}\text { The pyrolysis experiments were carried out } \\
\text { in a fixed bed design and stainless steel } \\
\text { reactor }(\mathrm{L} ; 210 \mathrm{~mm} \text {; O } 60 \mathrm{~mm}) \text { under } \\
\text { atmospheric pressure using a semi-batch } \\
\text { operation. The co-pyrolysis experiment was } \\
\text { performed at } 500^{\circ} \mathrm{C}\end{array}$ & $\begin{array}{l}\text { The pyrolysis of scrap tires at a temperature of } 500^{\circ} \mathrm{C} \\
\text { produced an oil yield of } 44.1 \mathrm{wt} \% \text {. The increase in oil yield } \\
\text { from co-pyrolysis processes of Pine wood and tire wastes } \\
\text { was found to be } 64.8 \mathrm{wt} \% \text {. The } \mathrm{HHV} \text { of tire waste pyrolysis } \\
\text { liquid alone was } 43.8 \mathrm{MJ} / \mathrm{kg} \text { while for the co-pyrolysis of } \\
\text { tire waste and pinewoods was } 46.8 \mathrm{MJ} / \mathrm{Kg} \text {. }\end{array}$ \\
\hline $\begin{array}{l}\text { Onenc et al., } \\
2012\end{array}$ & $\begin{array}{l}\text { Scrap tire (ST) samples } \\
\text { were shredded, crumbed } \\
\text { and sieved from the } \\
\text { sidewall rubber of scrap } \\
\text { tires to produce a size of } \\
1.5-2.0 \mathrm{~mm} \text {. The scrap tires } \\
\text { contained no steel thread or } \\
\text { textile netting. The average } \\
\text { rubber composition of the } \\
\text { scrap tires was } 35 \mathrm{wt} \% \\
\text { natural rubber and } 65 \mathrm{wt} \% \\
\text { butadiene rubber. The scrap } \\
\text { was mixed with a } \\
\text { pinewoods. }\end{array}$ & $\begin{array}{l}\text { A glass reactor with an internal diameter of } \\
30 \mathrm{~mm} \text { and a total length of } 350 \mathrm{~mm} \text { was } \\
\text { used in semi-batch operation under self- } \\
\text { generated pressure. Pyrolysis was performed } \\
\text { at } 400 \text { and } 500^{\circ} \mathrm{C} \text {. The ratio of the biomass } \\
\text { waste and tire waste was at the fixed ratio of } \\
1: 1\end{array}$ & $\begin{array}{l}\text { All experiments from pyrolysis of the individual } \\
\text { components showed that the maximum oil yields were } \\
\text { achieved at } 500{ }^{\circ} \mathrm{C} \text {. At } 500^{\circ} \mathrm{C} \text {, the oil was obtained at about } \\
71 \mathrm{wt} \% \text { for the pyrolysis of scrap tire. The oil yield of co- } \\
\text { pyrolysis of scrap tire and pinewood was around } 78.5 \mathrm{wt} \% \text {. }\end{array}$ \\
\hline
\end{tabular}

The presence of tire wastes in the co- pyrolysis of biomass has clearly improved the liquid yield. The pyrolysis of mixture of biomass and tire waste is able to produce extra liquid, typically between 1.42 and $22.2 \mathrm{wt} \%$. This finding was also supported by
Bridgewater, (2012) who mentioned that the increase in the yield of liquid products through co- pyrolysis may vary in the range of $2-23 \mathrm{wt} \%$. At the same time the energy content of the liquid represented by the calorific value showed a significant increase. Based on 
the data in Table 1, all types of tire wastes are known to improve the calorific value of the liquid product. However, the concentration of energy produced from the co - pyrolysis of bio-polymers was found to be lower compared to the oil produced from synthetic tires.

Economic Feasibility Assesment: Co-pyrolysis offers simplicity in design and operation, and in many cases has successfully produced oil with a high quantity and quality. Therefore, this technique can play a pivotal role in development of the biomass energy industry. There is an important note which showed that this technique is feasible from an economic point of view. Kuppens et al. (2010) used the net present value (NPV) to evaluate the economics of flash co-pyrolysis of $1: 1 \mathrm{w} / \mathrm{w}$ ratio blends of biomass (willow) and waste tires. NPV is the best analysis method for selecting or rejecting an investment, either industrial or financial (Pasqal et al., 2013; Graham and Harvey, 2011; Vanrepelen, 2011). The rule in this analysis was that the project would be accepted if the NPV was greater than or equal to zero, and would be rejected when the NPV was less than zero (Aziz, 2013). In this regard, the study performed by Kuppens et al. (2010) showed that flash co-pyrolysis of willow with waste tire was economically more interesting than flash pyrolysis of pure willow, because the NPV of co-pyrolysis resulted in positive cash flows for the co-pyrolysis of biomass and tire waste used. This result is supported by some other estimations as well, including the initial investment expenditure, the production costs, and the possible revenues. The author also noted that the calculations in this research paper were from a case study in Nigeria, but the economic model behind the case study can be adapted to other locations.

In addition, an economic evaluation of the copyrolysis process was also studied by Shelley and ElHalwagi (2017). A technoeconomic feasibility study was performed to assess the viability of co-liquefying scrap tires and biomass waste into liquid transportation fuels. The return on investment (ROI) approach was used to make investment decisions; if the ROI was positive then the investment was considered profitable. The authors noted that the co-liquefaction of biomass waste and waste tires as well as the liquefaction of scrap tires alone was both technically and economically feasible. The results showed promising economics for the mixed materials case with an ROI of approximately $18 \%$, as compared to only $12 \%$ for the plastics alone scenario. The author also reported that the tipping fees obtained for the raw materials used in the process were the key to overall profitability. Similarly, it is in agreement with another study performed in 1998 by Huffman and Shah (2016), who reported that the ROI depends on the tipping fees received for biomass waste and tire wastes. The high tipping fees received will be linearly contributed to the increase in ROI.

Discussion on Co-Pyrolysis Scenarios: This review showed that many researchers have studied the potency of co-pyrolysis technique using various types of biomass wastes, and that the results are very encouraging. Different investigations were conducted to obtain oil with a high yield and high quality, which followed the various available standards. Several advantages can be obtained from using this technique such as reducing the consumption of fossil fuels, solving some environmental problems, increasing energy security, and improving waste management systems. Apart from these, this technique also offers simplicity in design and feasibility in regard to economic analysis. There are some important factors which need to be highlighted in the feed system of the co-pyrolysis process. To obtain a high grade liquid, adjustments of the types and ratios of feedstock are essential. The suitable combination of feedstock in copyrolysis can include wood-based biomass with waste tires. This option is acceptable, since many studies have proven that these combinations can provide improvements in the pyrolysis oil through synergistic effects. Furthermore, it is important to note that the main aim of the addition of tire waste in the pyrolysis of wood-based biomass is to improve the quantity and quality of the oil produced. Hence, tire waste or scrap tires can be called the additive material in the process. In this regard, the proportion of additive material was designed to be less than that of the main feedstock (wood-based biomass). Many studies have shown that a higher ratio of additive material in the pyrolysis of wood-based biomass can contribute to increase the oil quality. However, the minimum use of additive material in each process of co-pyrolysis is preferred; this is due to some considerations such as:

- Besides being used as the additive material in copyrolysis, some wastes are also needed for the recycling process. This strategy will provide a benefit of reducing the consumption of fresh raw materials for the production new plastic, which leads to saving fossil fuel.

Co-pyrolysis is a promising technique that can produce a high grade pyrolysis oil from biomass waste. This technique also offers several advantages on its application:

- Co-pyrolysis can be easily applied to existing plants of the pyrolysis of biomass.

- Low cost associated with upgrading processes from pyrolysis to co-pyrolysis: if a plant is run for the pyrolysis of wood-based biomass, no money needs to be invested in a special plant for the use of waste tires. 
No special equipment needs to be designed and constructed for co-pyrolysis. Some minor modifications maybe needed, but only for the feed preparation system.

- As a byproduct, solid fuel is sometimes poor in organic matter; the addition of waste tires and to wood-based biomass may improve its quality.

- The quantity and quality of desired products (oil, solid, or gas) can be easily controlled by adjusting the process parameters.

- The primary disadvantage of co-pyrolysis lies in the biomass preparation unit. Given that this technique deals with many types of biomass, an additional pretreatment system is required, which can substantially increase the cost for the installation and operation of such units.

Conclusion: This review has focused on the study of co-pyrolysis techniques to produce high grade pyrolysis oil. The studies in the literature have been used to support the analysis and discussion in this paper. Many researchers have recognized that the copyrolysis technique can significantly improve the pyrolysis oil without the presence of any inert gas, catalysts or solvents and free hydrogen pressure. Therefore, this technique can be considered a simple, cheap, and effective method to obtain high-grade pyrolysis oil.

\section{REFERENCES}

Ac1kgoz, CA; Onay, O; Kockar, O (2015). Fast pyrolysis of linseed: product yields and compositions. J. Anal. Appl. Pyrol. 71:417-29.

Akhtar, JS; Saidina, A (2012). Review on operating parameters for optimum liquid oil yield in biomass pyrolysis. Renew Sust. Energy Rev. 16:5101-9.

Alias, RB; Hamid, K; Ismail, K (2018). Co-pyrolysis and catalytic co-pyrolysis of waste tires with oil palm empty fruit bunches. J. Appl. Sci. 11:244851 .

Agarwal, AF (2007). Biofuels (alcohols and biodiesel) applications as fuels for internal combustion engines. Prog Energy. Combust. Sci. 33:233-71.

Aziz, FA (2013). Optimizing strategy for repetitive construction projects within multi-mode resources. Alexandria Eng J. 52:67-81.

Bridgwater, AV (1999). Principles and practice of biomass fast pyrolysis processes for liquids. $J$. Anal. Appl. Pyrol. 51: 3-22.
Bridgwater, AV (2012). Review of fast pyrolysis of biomass and product upgrading. Biomass Bioenergy. 38:68-94.

Bridgwater TC (2006). Biomass for energy. J Sci. Food Agric. 86:1755-68.

Cao, QF; Jin, LE; Bao, W; Lv, Y (2017). Investigations into the characteristics of oils produced from co-pyrolysis of biomass and tire. Fuel Process Technol. 90:337-42.

Demiral, ID; Sensoz, S (2006). Fixed-bed pyrolysis of hazelnut (Corylus Avellana L.) bagasse: influence of pyrolysis parameters on product yields. Energy Source Part A. 28:1149-58.

Garforth, AA; Ali, S; Hernndez, JS; Akah, A (2004). Feedstock recycling of tire wastes. Cur. Opin. Solid State Mater Sci. 8:419-25.

Graham, JR; Harvey, CR (2001). The theory and practice of corporate finance: evidence from the field. J Financ Econ. 60:187-243.

Huffman, GP; Shah, N (2016). Feasibility study for a demonstration plant for liquefaction and Coprocessing of waste plastics and tires. Chem. Tech. 28:34-41.

Kuppens, TL; Cornelissen, T; Carleer, R; Yperman, J; Schreurs, S; Jans, M (2010). Economic assessment of flash co-pyrolysis of short rotation coppice and biopolymer waste streams. J Environ Manage. 91:2736-47.

Martinez, JD; Veses, A; Mastral, AM; Murillo, R; Navarro, MV; Puy, N (2017). Copyrolysis of biomass with waste tires: upgrading of liquid biofuel. Fuel Process Technol. 119:263-71.

Manzo, AH; Agugliaro, F; Alcayde, A; Montoya, FG; Zapata-Sierra, A; Gil, C (2013). Scientific production of renewable energies worldwide: $A n$ overview. Renew Sust Energy Rev. 18:134-43.

Moreira, JC (2006). Global biomass energy potential. Mitig. Adapt. Stra. Glob. Change. 11:13-33

Onenc, SU; Brebu, M; Vasile, C; Yanik, J (2012). Copyrolysis of scrap tires with oily wastes. $J$. Anal Appl. Pyrol. 94:184-9.

Ucar, SA; Karagoz, S; Yanik, J; Saglam, M; Yuksel, M (2005). Copyrolysis of scrap tires with waste 
lubricant oil. Fuel Process Technol 2005;87:5378.

Silva, MB; Onenc, S; Ucar, S; Yanik, J (2013). Influence of oily wastes on the pyrolysis of scrap tire. Energy Convers Manage. 75:474-81.

Oasmaa, AM; Czernik, S (1999). Fuel oil quality of biomass pyrolysis oils-state of the art for the end users. Energy Fuel. 13:914-21.

Parihar, MF; Kamil, M; Goyal, HB; Gupta, AK; Bhatnagar, AK (2007). An experimental study on pyrolysis of biomass. Process Saf Environ Prot. $85: 458-65$.

Pasqual, JT; Padilla, E; Jadotte, E (2013). Technical note: Equivalence of different profitability criteria with the net present value. Int J Prod Econ. 142: $205-10$.

Quek, AC; Balasubramanian, R (2017). Liquefaction of waste tires by pyrolysis for oil and chemicals - a review. J Anal. Appl. Pyrol. 101:1-16.

Williams, PT (2017). Pyrolysis of waste tires: a review. Waste Manage. 33: 1714-28.

Shafiee, SK; Topal, E (2009). When will fossil fuel reserves be diminished? Energy Policy.37:181-9

Shelley, MD; El-Halwagi, MM (2017). Technoeconomic feasibility and flowsheet synthesis of scrap tire/plastic waste liquefaction. $J$ Elastom Plast 31:232-54.
Toba, MA; Abe, Y; Kuramochi, H; Osako, M; Mochizuki, T; Yoshimura, Y (2011). Hydrodeoxygenation of waste tires over sulfide catalysts. Catal Today 164:533-7.

Veses, AS; Aznar, M; Martinez, I; Martinez, JD; Lopez, JM; Navarro, MV(2014). Catalytic pyrolysis of wood biomass in an auger reactor using calcium-based catalysts. Bioresour Technol.162:250-8.

Venderbosch, RH; Prins, W (2010). Fast pyrolysis of biomass for energy and chemicals: technologies at various scales. Sustainable development in the process industries. John Wiley \& Sons, Inc.; 2010. p. 109-55.

Vitolo, SP; Seggiani, M; Frediani, P; Ambrosini, G; Politi, L (1999). Catalytic upgrading of pyrolytic oils to fuel over different zeolites. Fuel; 78: 114759.

Vamvuka, DB (2011). Bio-oil, solid and gaseous biofuels from biomass pyrolysis processes - an overview. Int J Energy Res; 35:835-62.

Velghe, IB; Carleer, R; Yperman, J; Schreurs, S (2015). Study of the pyrolysis of municipal solid waste for the production of valuable products. $J$ Anal Appl Pyrol; 92:366-75.

Vanreppelen, KP; Kuppens, T; Thewys, T; Carleer, R; Yperman, J; Schreurs, S (2011). Activated carbon from co-pyrolysis of particle board and melamine (urea) formaldehyde resin: a techno-economic evaluation. Chem Eng J 172:835- 46. 